\title{
La digitopuntura es eficaz para tratar pacientes con lumbalgia crónica
}

Hsieh L. y col. BMJ,2006; 332: 696-700.

\section{Objetivo}

Evaluar la efectividad de la digitopuntura para el tratamiento de la lumbalgia crónica.

Diseño

Ensayo clínico aleatorizado y controlado.

Lugar

Clínica ortopédica en Kaohsiung, Taiwán.

\section{Pacientes}

Se incluyeron 129 pacientes con dolor lumbar de más de cuatro meses de evolución, diagnosticado por especialista. Se excluyeron pacientes con causas secundarias de lumbalgia, enfermedad sistémica u orgánica, cáncer, enfermedad psiquiátrica, embarazadas, dolor agudo con requerimiento de tratamiento inmediato o cirugía y pacientes con contraindicación para digitopuntura. Fueron aleatorizados 64 pacientes a digitopuntura y 65 a kinesioterapia.

\section{Intervención}

Seis sesiones de digitopuntura durante un mes (realizada por un sólo profesional especializado) o kinesioterapia (tracción pélvica manual, manipulación espinal, termoterapia, terapia con luz infrarroja, estimulación eléctrica).

\section{Medición de Resultados Principales}

Se utilizó para la medición del resultado principal el cuestionario de Roland y Morris, validado internacionalmente para evaluar el grado de discapacidad producida por el dolor lumbar. Las mediciones fueron realizadas al inicio, al final del tratamiento y a los seis meses de haberse finalizado el mismo. Se consideró que un puntaje de 0 a 12 en el cuestionario implicaba discapacidad mínima y un total de 13 a 24, discapacidad significativa. El análisis se realizó por intención de tratar.

\section{Resultados Principales}

Luego del tratamiento y transcurridos seis meses del mismo, tuvo mejor evolución el grupo de pacientes asignado a digitopuntura, con un beneficio atribuible a la intervención de 3,8 (IC95\%: 5,7-1,9) por cada 100 tratados.

La diferencia promedio entre el puntaje inicial y el posterior al tratamiento fue - 4,64 (IC95\%: $-6,39--2,89)$.

La digitopuntura se asoció a un 89\% (IC95: 61-97\%) de reducción de discapacidad significativa en relación a la kinesioterapia. Ver tabla 1.

Tabla 1. Puntajes de discapacidad de Roland y Morris al inicio, al finalizar el tratamiento y a los seis meses de concluido el mismo.

\begin{tabular}{|c|c|c|c|c|c|}
\hline \multicolumn{2}{|c|}{$\begin{array}{l}\text { Grado de discapacidad según el puntaje } \\
\text { de Roland y Morris }\end{array}$} & $\begin{array}{c}\text { Digitopuntura } \\
(n=64)\end{array}$ & $\begin{array}{l}\text { Kinesioterapia } \\
\text { (n=65) }\end{array}$ & $\begin{array}{l}\text { OddsRatio } \\
\text { (IC 95\%) }\end{array}$ & p \\
\hline Antes del tratamiento & $\begin{array}{c}\text { Mínima (0-12) } \\
\text { Signnificadiva (13-24) }\end{array}$ & $\begin{array}{l}36 \\
28\end{array}$ & $\begin{array}{l}45 \\
20\end{array}$ & 1 & - \\
\hline Luego del tratamiento & $\begin{array}{c}\text { Mínima (0-12) } \\
\text { Significativa (13-24) }\end{array}$ & $\begin{array}{c}56 \\
8\end{array}$ & $\begin{array}{l}46 \\
19\end{array}$ & $0,11(0,03-0,39)$ & Menor a 0,001 \\
\hline $\begin{array}{l}\text { A los seis meses del } \\
\text { tratamiento }\end{array}$ & $\begin{array}{c}\text { Mínima (0-12) } \\
\text { Significadiva (13-24) }\end{array}$ & $\begin{array}{c}63 \\
1\end{array}$ & $\begin{array}{l}57 \\
8\end{array}$ & $0,07(0,01-0,57)$ & Menor a 0, C \\
\hline
\end{tabular}

\section{Conclusión}

La digitopuntura es efectiva para la reducción del dolor lumbar crónico y la discapacidad que éste produce. Este beneficio se mantiene seis meses luego de concluído el tratamiento.

Fuente de financiamiento: ninguna

\section{Comentario}

La digitopuntura es una técnica de la Medicina Tradicional China que consiste en la estimulación de puntos específicos en el cuerpo mediante presión digital. Este artículo la aplica al tratamiento de la lumbalgia crónica, motivo de consulta muy frecuente en atención primaria'. La lumbalgia crónica produce discapacidad y es una de las causas principales de ausentismo laboral. Muchas veces es rebelde al tratamiento convencional y por eso es frecuente que los pacientes recurran y consulten por terapias alternativas como la acupuntura o digitopuntura.

Este trabajo, metodológicamente correcto, muestra la efectividad de la digitopuntura para reducir el grado de dolor y de discapacidad en pacientes con lumbalgia crónica, pero hay ciertos puntos que merecen analizarse en detalle: los autores no aclaran si hubo cointervenciones ${ }^{*}$ como la utilización de analgésicos, hecho importante al evaluar dolor como punto final del estudio; tampoco mencionan qué terapia física recibieron los pacientes que fueron asignados a la rama "kinesiología"; ni los puntos utilizados para la di- gitopuntura, sólo aclaran que fue un único digitopunturista quién realizó el tratamiento. Estos datos habrían mejorado la validez externa o aplicabilidad de los resultados.

\section{Conclusión de los comentadores}

La digitopuntura es una alternativa para el tratamiento de pacientes con lumbalgia crónica que, practicada por un profesional idóneo², no produce ningún efecto adverso. Podríamos considerarla para pacientes que no responden al tratamiento convencional o como complemento de éste. Resulta difícil elegirla como primera opción ya que este trabajo no nos aporta datos sobre la técnica precisa a realizar, pudiendo requerir la intervención de expertos reales en la materia. Asegurar la idoneidad del experto no suele ser tarea fácil, ni se encuentra accesible para todos los pacientes.

Gonzalo Yamauchi y Ariana Cheng [ Unidad de Medicina Familiar y Preventiva. Hospital Italiano de Buenos Aires. ]

Yamauchi G y Cheng A. La digitopuntura es eficaz para tratar pacientes con lumbalgia crónica. Evid. actual. práct. ambul. 9(4) ;108. Jul-Ag. 2006. Comentado de: Hsieh L, Kuo CH, Lee LH, Yen AM, Chien KL, Chen TH. Treatment of low back pain by acupressure and physical therapy: randomised controlled trial. BMJ.2006 Mar 25;332 (7543): 696-700. PMID: 16488895.

\section{Referencias}

1. Koes B. et al. Managing low back pain BMJ 2006;332:1430-1434 (17 June). doi: 10.1136/bmj. 332.7555.1430.

2. Hsieh L, Kuo CH, Yen MF, Chen THH. A randomized controlled clinical trial for low back pain treated by acupressure and physical therapy. Prev Med $2004 ; 39$ : 168-76. 